\title{
Analysis on Bilingual Public Signs in the View of Audience Theory-A Case Study of City Traffic Public Signs in Xi’an
}

\author{
Wenmin Li' ${ }^{1}$, Xue Wang1, Shihan Hou ${ }^{2}$ \\ ${ }^{1}$ Shaanxi University of Science \& Technology, Xi'an, China \\ ${ }^{2}$ Haojing College of Shaanxi University of Science and Technology, Xi'an, China \\ Email: yezi wm66@163.com
}

Received 24 February 2015; accepted 10 April 2015; published 15 April 2015

Copyright (C) 2015 by authors and Scientific Research Publishing Inc.

This work is licensed under the Creative Commons Attribution International License (CC BY). http://creativecommons.org/licenses/by/4.0/

(c) (7) Open Access

\begin{abstract}
This paper, with the audience theory as its theoretical guide and by taking a case study on Bilingual traffic Public Signs in Xi'an, especially on bilingual station names of Xi'an Metro Line 2, first briefly discusses how an important role city traffic public signs play in serving the audience, facilitating tourism as well as disseminating Chinese culture through the international audience. Second, it analyzes the problems existing in the present bilingual public signs in China and the counter-productive effects they are likely to bring about. And finally proposal for a new system of bilingual station names of Xi'an Metro Line 2 is put forward, which, the author believes, will not only offer the exact information wanted but make the audience abroad feel at home.
\end{abstract}

\section{Keywords}

\section{Audience Theory, Communication Effect, Bilingual Public Signs, Xi'an Metro, Subway Station} Names

\section{Introduction}

Standard bilingual (both Chinese and English) public signs, practical texts applied in public places, are widely believed as a kind of bilingual landscape (Wang, 2013) which symbolizes how open-minded a city is to the outside world and how well it internationalizes. They function as passing on information such as information of direction guide, reminders, introductions, warnings and ads. City traffic signs including subway station names both in Chinese and English are essential part of bilingual public signs. So it does matter whether bilingual traffic signs locating the directions can lead the foreign audience to almost the same feeling as the native in Chinese 
history and culture embedded in traffic signs so as to achieve communication effect both in meaning and feeling.

Xi'an, rich in history and local culture, has taken great efforts to step on its way to internationalized metropolis. Xi'an Metro (subway) may be a passage presenting the ancient city's profound history and its grand internationalization. Xi'an Metro Line 2 was open to traffic in 2011. And its bilingual station names, especially its English equivalents, since the first day they were released to public, have always been the focus and thus attracting hot discussion among the audience both abroad and at home.

\section{Brief Introduction of Audience Theory}

Audience in communication theories refer to receivers in various kinds of communication activities, that is to say, readers, listeners and spectators in general. Audience (Berelson, 1959 \& Klapper, 1960) were once materialized in early audience theories such as in "hypodermic needle theory" and "magic bullet theory". Magic bullet theory thought that the disseminator, like a shooter, played an active and leading role in the process of communication. While the audience, set as the target by the disseminator, had to accept whatever information sent to them with no choice. According to the above theories, the communication (Tang \& Guo, 2010) is one-way only from its disseminators to its receivers, and its audience are completely passive in its process. While modern audience theories show quite different ideas.

With the development of the international communication and its further study, modern audience theories highlight the audience, the information receivers. For audience, as is obviously believed, are not only the source of communication, the feedback center in communication process but the terminal of communication blends together with psychology, philosophy and sociology etc., and due to the popular ideas such as those of "individual difference", "social relationship", and "demand and satisfaction", communication has been remarkably developed and audience have existed both as the center of communication and attention of the modern researchers. Many famous representatives from the Euro-American critical theory school including ML DeFleur and Denis McQuail much more value the communication effect. They hold that the audience are not the pure receivers, and actually they are participators in the process of communication. The disseminators and the audience interact with each other via the media. Since audience have different understanding about the same message for individual difference and different benefit groups they belong to, the level of the communication effect (Defleur, 1990) can be evaluated not mainly by how much information the disseminator mean to impose upon the audience but by what the information is and how much information the audience are willing to accept in the communication process. So conclusively, It is the participation of the audience and the active interaction between the disseminator and the audience that take the communication into effect. In the era of mass communication, the power of the audience could be much more felt everywhere. Whoever grasps the attention of the audience will undoubtedly possess the communication market and share the communication effect.

Therefore, the central position of the audience in the process of communication can't be neglected. Modern audience theory aims at guiding the disseminators to better the communication effect by fully recognizing the subjective initiative and the main-body function of the audience in the process of communication.

\section{Communication Function of Bilingual Public Signs}

Public signs include traffic signs, reminders, ads and so on, which mean to offer geographic guide, polite warnings, and other useful information concerning our daily life to the public. Public signs belong to the category of mass media. Unlike other public signs, city traffic public signs concern nearly everyone unless he isolates from the outside world. Because of the worldwide use of English language , the progress of global village and the fast development of Chinese economy, bilingual city traffic public signs (both in Chinese and English), with people of the world as its potential and target audience, are essential in big cities of China. Xi'an, one of the greatest ancient cities in the world, is with no exception.

Proper city traffic public signs in English function a lot, such as offering exact geographic guide so as to facilitating tourism to foreign audience, improving language environment, promoting cultural tastes of the city, creating convenient English learning atmosphere for the natives and embodying Chinese culture and worldwide transmitting it through foreign audience. Only when the audience both abroad and at home are put in the first place of consideration can city traffic public signs exert the above effective functions. Proper or not, that depends on the audience. However, like other public signs in English, many problems exist in current English city traffic public signs, especially those in subway stations. 


\section{Problems Existing in Bilingual City Traffic Station Names}

City traffic station names consist of the ground traffic station names and those of the underground (subway). The development level of the transportation network of a city is closely relevant to that of the city's economy. The names of a city's traffic public stations (Yang, 1999) would, in a sense, stand for the tastes of the local culture, the unique way of communication and the degree of its openness to the outside world. Meanwhile, they serve as a bridge connecting the Chinese culture with its foreign audience, and its native audience with the culture of English speaking countries as well. However, the only employment of Chinese names in ground traffic stations in most of the big cities in China could neither adapt to the changing environment nor meet the demand from the audience both abroad and at home. What's worse, it will, to some degree, spoil the international image of the city. The bilingually named subway stations have become bilingual landscape in most of the big cities in China. But actually, most of them are in Chinese Pinyin, (Cao, 1989) which would not be understood and hardly accepted by the foreign audience. Pitifully enough, those in favor of employing Chinese Pinyin as the form of English suggest that it is a kind of localized English and an effective way to disseminate Chinese culture. It's true of the city traffic station names which are really geographical places or those with local features. What if a traffic public station named after a communal facility nearby like city library is translated into Chinese Pinyin like SHI TUSHUGUAN? Consequently, it's hard to achieve the goal of the traffic public signs effectively. Bilingual station names of Xi'an Metro Line 2 are a good case in point. To sum up, whether we adopt Chinese Pinyin or English equivalents depends on what the station name is, and what can be acceptable to the audience.

Xi'an, as mentioned in the part of Introduction, rich in history with the experience of 13 ancient dynasties, famous for its tourism with numerous historic sights and centered both strategically and geographically in Great Development of Western China, has been positioned as a potential internationalized metropolis with its distinctive historical culture .

Objectively, besides meeting the new challenge, Xi'an is faced with quite a few problems in traffic public signs which are common to other Chinese big cities: no English equivalents for ground traffic station names, only Chinese Pinyin for the metro traffic station names, to name a few, like BEIKEZHAN, SHI TUSHUGUAN, and what's more, the same location, but two different names on ground and underground, 北门站 and 南门站 on ground, but 安定门站 (ANDINGMEN) and 永宁门站 (YONGDINGMEN) underground. That confused the native audience, let alone the foreign audience.

\section{Culture Communication of Bilingual Station Names of Xi'an Metro Line 2}

In recent years, city transportation has developed rapidly, especially rail rapid transit. Xi'an Metro Line 2 of the first phase has been in use for more than 2 years. Five more metro lines together with more than 110 stations and 16 transfer stations will be planning to be built soon. Xi'an Metro lines will function as urban public transportation junction in the progress of internationalized metropolis. Bilingual subway station names in Xi'an, especially those in English, take a magnificent function in embodying Chinese culture and bridging Xi'an with the outside world. Xi'an Metro Line 2 is now leading the way. Bilingual station names of Xi'an Metro Line 2 mean a lot, as they will not only function as an access both for the native audience to the outside world and for the foreign audience to Xi'an, the history-rich city but also be the guide to those of other metro lines following.

\subsection{Station Names of Xi'an Metro Line 2 in Chinese}

Subway station names (Mei, 2008) should first show clear and exact guide of directions, and then they should embody the city's distinctive local features. Finally, they must also be in a harmonious and agreed system with those of the ground traffic stations, which is the major problem existing in some of the traffic station names on ground and underground in Xi'an such as the same location named 北门站 on ground and 安定门站 (ANDINGMEN) underground.

Currently, there are 23 subway stations of Xi'an Metro Line 2 in the first phase of the project. The Chinese subway stations of Xi'an Metro Line 2 aim at the natives and the foreign audience who know Chinese well. Three main characteristics can be summed up according to the currently used Chinese subway stations of Xi'an Metro Line 2. 1) Named after large functional sites or public facilities so as to be easily found, such as City Library and Sports Park. 2) Named after the names of familiar places or streets to the native audience, such as North Street and XIAOZHAI. 3) named after old names in history so as to rouse the sense of historical culture, 
such as ANDING Gate ( Northern Gate of the ancient city in Ming Dynasty) .

Subway station names of Xi'an Metro Line 2 in Chinese have fully performed humanized communication of audience-centered idea and will provide practical reference and theoretic guide to other metro lines to be built.

\subsection{Analysis on Station Names of Xi'an Metro Line 2 in English}

Due to the rich connotation of natural and social culture in traffic station names, English station names are more than symbol transform from Chinese. They well exert function to pass on the cultural connotation they contain. Station names from Chinese into English should adopt pronunciation-based translation. Meanwhile Nada's Principle of Equivalence must be taken into consideration in the process of translation in order to establish the sense of audience and to culturally achieve effect of the communication.

Language is A means of human communication. Disseminators pass the information by language symbols on their receivers. Receivers comprehend it through the specific context where the language symbols exist. Only under the condition (Pi, 2010) that the translator faithfully represents the original meaning of the text and fully grasp the main characteristics of the receivers in the process could the foreign receivers get the same feeling with the information in target language as the native with that in source language.

The station names of Xi'an Metro Line 2 have completely employed Chinese Pinyin instead of English translation. It's OK to some of the station names if they are names of geographical places, but not to those standing for public facilities. Chinese Pinyin through the whole metro line is meaningless to the native audience and not understandable to the foreign audience. Some signs like Xiaozhai and XIAOZHAI ZHAN referring to the same station appear in different exits confuse foreign audience more.

Investigation including questionnaires, interviews and relevant information searched from the internet has been made about currently used bilingual station names of Xi'an Metro Line 2. 5000 electronic questionnaires have been released through email to local college teachers and students from Class 2010 to Class 2012 including foreign teachers and foreign students, and 4143 of which were responded. 1500 paper questionnaires (both in Chinese and in English) have been released to the passengers on Xi'an Metro Line 2, and all of them got immediate response. 1000 native passengers and 300 foreign passengers on Xi'an Metro Line 2 were effectively interviewed. The investigation is made in the way of 4 listing questions and one blank and three possible choices to each question. The major content of the investigation (in English) is shown in the following table. Accordingly, $89 \%$ of the people investigated (including 99\% of the foreigners) think that the currently used English names are unsatisfying, with less than 5\% show never mind attitude. In volume 2, 85\% (including 100\% of the foreigners) chose $\mathrm{C}$ and $11 \%$ chose A. People who chose A think it's a good chance to disseminate Chinese culture and to make English localized. 91\% chose A in Volume 3 and B in Volume 4 (including 99\% of the foreigners). Less than $15 \%$ filled in the blank of $\mathrm{D}$ in each volume and $62 \%$ of the investigated people gave proposals in detail points (including $73 \%$ of the foreigners). Most of the people who made comment on the traffic station names of Xi'an Metro Line 2 on the internet share similar ideas with most of the audience investigated.

Table 1 is the questionnaire of investigation to the English Station Names in Xi'an Metro Line 2.

\subsection{Translation Strategy for Station Names of Xi'an Metro Line 2}

The purpose of subway station names both in Chinese and English is to instruct the directions, disseminate local or national culture and serve the audience. That leads the Chinese names and English equivalents to audiencecentered principle. Translation of the station names (Lv, 2005) should exert the same influence on the foreign audience as Chinese names do on the native audience. Theory of dissimilation and assimilation by Lawrence

Table 1. Questionnaire of investigation to the English station names in Xi'an Metro Line 2.

\begin{tabular}{|c|c|c|c|c|}
\hline $\begin{array}{l}\text { Currently used } \\
\text { English names }\end{array}$ & $\begin{array}{l}\text { Names of the } \\
\text { whole line }\end{array}$ & $\begin{array}{l}\text { Names of places } \\
\text { and of streets }\end{array}$ & $\begin{array}{l}\text { Names standing for } \\
\text { public facilities }\end{array}$ & Proposals \\
\hline A. Satisfying & A. In Chinese Pinyin & A. In Chinese Pinyin & A. In Chinese Pinyin & \\
\hline B. Unsatisfying & B. In English & B. In English & B. In English & \\
\hline C. Never mind & C. That depends & C. Never mind & C. Never mind & \\
\hline D. Others & D. Others & D. Others & D. Others & \\
\hline
\end{tabular}


Venuti can meet such a demand and therefore should be followed in translation process. Dissimilation means remaining the typical features of the source language in target language in the process of translation so as to lead the target audience to the feeling of the local tradition and culture. And assimilation refers to changing the style of the source language which carry the information and pass on the information in the target language style familiar to the target audience so that the information can be easily caught by the target audience. Some station names are adapted to the way of dissimilation so as to present the local features to the foreign audience. While some others are proper if translated in the way of assimilation in order to create an atmosphere in which the foreign audience will feel at home.

China issued "translation standard for signs of geographical names" in 1999, which set Chinese Pinyin for geographic names in China and that also conform to the international practice " translation based on standard pronunciation".

According to the features of Xi' an Metro station names, those named after geographic names accord well with Chinese Pinyin, so way of dissimilation can be employed to make the foreign audience better understand Chinese culture. Those named after large functional sites apply international practice for translation, and therefore way of assimilation can be employed in this case. In addition, way of assimilation suits words like directional words, words of ordinal numbers, street, lane and so on. So it's unreasonable to employ Chinese Pinyin for the station names through the whole metro line. Some have to be altered so as to achieve the goal of clear guide of direction and communication effect. Of course, Chinese way of writing to capitalize every letters should be employed here.

In stead of employing Chinese Pinyin through the whole line, the more satisfying way of translation are put in the following.

1) XI'AN NORTH RAILWAY STATION; 2) BEIYUAN; 3) SPORTS PARK;

4) ADMINISTRATIVE CENTER; 5) 5TH. FENGCHENG ST.; 6) CITY LIBRARY;

7) DAMING PALACE W.; 8) LONGSHOUYUAN; 9) ANYUAN GATE; 10) NORTH ST.;

11) BELL TOWER; 12) YONGNING GATE; 13) NANSHAO GATE; 14) SHAANXI STADIUM;

15) XIAOZHAI; 16) WEIYI ST.; 17) INTERNATIONAL EXPO CENTER; 18) SANYAO:

19) FENGQIYUAN; 20) SPACEFLITHT TOWN; 21) WEIQU S.:

22) WEIHE METRO GARAGE; 23) JUHE METRO PARKING.

\section{Conclusion}

From the case study of city traffic public signs in Xi'an ,especially traffic station names of Xi'an Metro Line 2, bilingual public signs will function as a window of a city to display its local and distinctive culture and a bridge between the city and the outside world if they are completed in the way which can be acceptable to the audience abroad and at home. With the economy internationalized, culture diversified and communication worldwide progressed, international audience will better perform their subjunctive initiative in the process of communication. The disseminators will fully realize that the audience are the centered but not the only part of the communication and the communication effect will be greatly dependent on what and how much the audience accept.

\section{Funding}

This paper is financed both by project of Xi'an City Science \& Technology Bureau named Research on Cultural Connotation of Xi'an Metro Bilingual Public Signs in the Context of Internationalization (SF1227-3), and by project of Xianyang City Science \& Technology Bureau named Research on Economical and Cultural Value of the Public Signs Under the Integration of Xi'an and Xianyang (2011K13-07).

\section{References}

Berelson, B. (1959). The State of Communication Research. Public Opinion Quarterly, 23, 1-2.

Cao, S. Y. (1989). Discussion on the Names of the Location in China. Chinese Translators Journal, No. 3, 48-51.

Defleur, M. L. (1990). Theories of Mass Communication. Peiking: Xinhua Publishing House.

Klapper, J. T. (1960). The Effects of Communication. New York, NY: Free Press.

Lv, H. F. (2005). On Functional Features and Chinese-English Translation of the Expressions on Public Signs. Terminology Standardization \& Information Technology, No. 2, 21-27. 
Mei, X. J. (2008). Choice of the Purpose of Translation and Its Strategy. Foreign Language Research, No. 2, 127-130.

Pi, D. M. (2010). Study on Public Signs and the Chinese-English Bilingual Translation Principles. Foreign Language Research, No. 2, 132-134.

Tang, K. X., \& Guo, R. (2010). Discussion on the Correlation between Audience Theory and the Acceptance of Ideological and Political Education. Guiyang Normal University Journal.

Wang, J. J. (2013). Linguistic Landscape of China: A Case Study of Shop Signs in Beijing. Studies in Literature and Language, 6.

Yang, X. J. (1999). Comparison between Eastern and Western Culture Implied in Geographical Names and the Translation Strategies. Xiangtan Normal University Journal. 